\title{
The Trend of Institutional Research in Japanese Medical Education: A Case Study from Jichi Medical University
}

\author{
Yoshikazu Asada*
}

\begin{abstract}
The importance of IR (institutional research) has seen a recent increase in the field of medical education. The main reason for this trend is the need for accreditation of medical education based on global standards. In this paper, the current IR system, including the structure and contents of databases, and IR topics of the Jichi Medical University are described. Although there are useful previous studies on IR, medical universities and colleges have specific aspects that may not have been covered by previous studies. Further studies are therefore needed in this research field.

Keywords: Accreditation, institutional research, medical education, medical university, program evaluation, system development

\section{Introduction: Medical Education and Institutional Research}

In recent times, institutional research (IR) has become one of the trends of medical education in Japan. This trend is mainly because of the need for program evaluation based on global standards of basic medical education. Although there are several previous studies and works on institutional research, their findings may sometimes not be suitable for medical education because of the particularity of the medical education system.
\end{abstract}

\subsection{Medical Education and Accreditation}

In 2010, the United States Education Commission for Foreign Medical Graduates (ECFMG) announced that from 2023 onward, physicians applying for ECFMG Certification will be required to graduate from a medical school that has been appropriately accredited [1]. Although not many physicians apply for ECFMG from Japan, this announcement revealed the need for program evaluation of medical education. In fact, many Japanese universities and colleges must improve their curriculum and adapt them to match international standards.

In Japan, the Japan Accreditation Council for Medical Education (JACME) was established in 2013. In 2017, the World Federation for Medical Education (WFME) recognized JACME as the organization for accreditation of basic medical education schools or programs in Japan. Thus,

\footnotetext{
* Center for Information, Jichi Medical University, Tochigi, Japan
} 
JACME started to evaluate the medical education program in Japan based on "Basic Medical Education: Japanese Specifications" [2].

Based on the global standards of medical education, IR is closely connected, especially, to area 7, which is "Programme Evaluation." Although there is no "institutional research" or IR mentioned in the standards, the annotations about "Programme monitoring" and "Programme evaluation" state the need for IR. For example, "Programme monitoring" is described as follows:

"Programme monitoring would imply the routine collection of data about key aspects of the curriculum for the purpose of ensuring that the educational process is on track and for identifying any areas in need of intervention. The collection of data is often part of the administrative procedures in connection with admission of students, assessment, and graduation. [3]."

From this annotation, it is clear that collection of data is one of the most important tasks of IR. However, only a few medical universities and colleges in Japan have established an IR section. The results of accreditation of many colleges show that on evaluation of their current status, they received feedback for establishing and managing IR to improve their educational system [4]. This situation could have arisen from their lack of knowledge in the medical education field about managing and building an IR system.

Furthermore, differences are seen between IR in medical education and in non-medical education. IR treats not only education but also finance and research data. However, since the accreditation is focused only on the evaluation of education, most IR in medical universities and colleges are about educational IR. Sometimes there are more than two IR offices in a single university, such as the IR for whole university and the IR for medical education. Thus, there is a need for not only general IR management knowledge but also specific, medical educational IR.

In fact, other eight areas of global standards are also connected to IR. The nine areas of global standards are the following:

Area 1: Mission and outcomes

Area 2: Educational programme

Area 3: Assessment of students

Area 4: Students

Area 5: Academic staff/faculty

Area 6: Educational resources

Area 7: Programme evaluation

Area 8: Governance and administration

Area 9: Continuous renewal

Each area has a few sub-areas, and there are 35 sub-areas overall. For example, area 1 has four sub-areas such as "mission" and "educational outcomes." On the other hand, the following roles 
of IR are described by the "IR golden triangle" [5]:

1. Institutional reporting

2. Policy analysis

3. Planning

4. Enrollment

5. Financial management

6. Outcome assessment

7. Programme review

8. Effectiveness

9. Accreditation

The IR golden triangle dominates most of the practice of IR in the United States. It includes three analytical functions: (1) institutional reporting and administrative policy analysis; (2) strategic planning, enrollment, and financial management; and (3) outcomes assessment, programme review, accountability, accreditation, and institutional effectiveness.

Although these two are not the same, they are connected to each other. For example, Area 1 is related to "Policy analysis" and "Outcome assessment." Thus, in medical education in Japan, IR is mainly used in the educational context as enrollment management and curriculum evaluation, including longitudinal study.

\subsection{About Jichi Medical University (JMU)}

This paper describes the current IR situation in Jichi Medical University (JMU). JMU was established in 1972 to ensure and improve the level of medical services provided in rural areas that lack medical resources [6]. JMU has three missions to train medical professions to fulfill its mandate of "Bringing the Light of Community Medicine to Communities":

1) To conform to the highest standard of ethics and professionalism.

2) To provide high-level medical and comprehensive clinical knowledge to respond to various health challenges throughout their practice.

3) To work in under-served areas, lead community wellness, and make positive social contributions.

Although JMU is one of the many medical universities in Japan, it has some specific features [7]. For example, JMU takes two to three students from every prefecture every year. After graduation, these students will be required to return to their prefecture to work for medical institutions for at least nine years, including rural dispatch. This nine-year working will exempt them from their entire school fee. 
Another specific feature is the dormitory in the university. Every student is required to stay in the dormitory after entering JMU. Not just during classes, but also after that students are able to study together. This feature might have an effect on their educational outcome.

In this paper, the following are described regarding the current situation of IR in medical education, including the difference between IR in medical education and IR in non-medical education:

(1) the current IR system of JMU, such as its database structure

(2) the current research topics of JMU IR

\section{IR system of JMU}

The IR section of JMU was established in 2016 [8]. The Center for Information aims to improve the network infrastructure to promote campus-wide adoption of information technology and to facilitate communication with alumni who are spread throughout Japan. That is, the IR section is not within the Medical Education Center or under the academic dean.

This is because of the separation of power. Global standards recommend that the section for data management and analysis such as IR should be separate from the decision-making section such as the medical education center or educational committee.

The IR section collects various kinds of data such as grades of students, attendance rates, and the learning data from Moodle. Previously, these data were managed by different sections. Since the IR section was established, much of the data were gathered into the section. Since all data related to students have students' ID number as the common key, it becomes easy to add or filter data.

There are three databases for IR at JMU as shown in Figure 1: (1) MySQL-based IR database for gathering and storing data from other sections, (2) Moodle as LMS (Learning Management System), and (3) LRS (Learning Record Store). Since the LRS is still under trial and is now used only for storing the learning log from Moodle, this paper treats mainly the IR database and Moodle. 


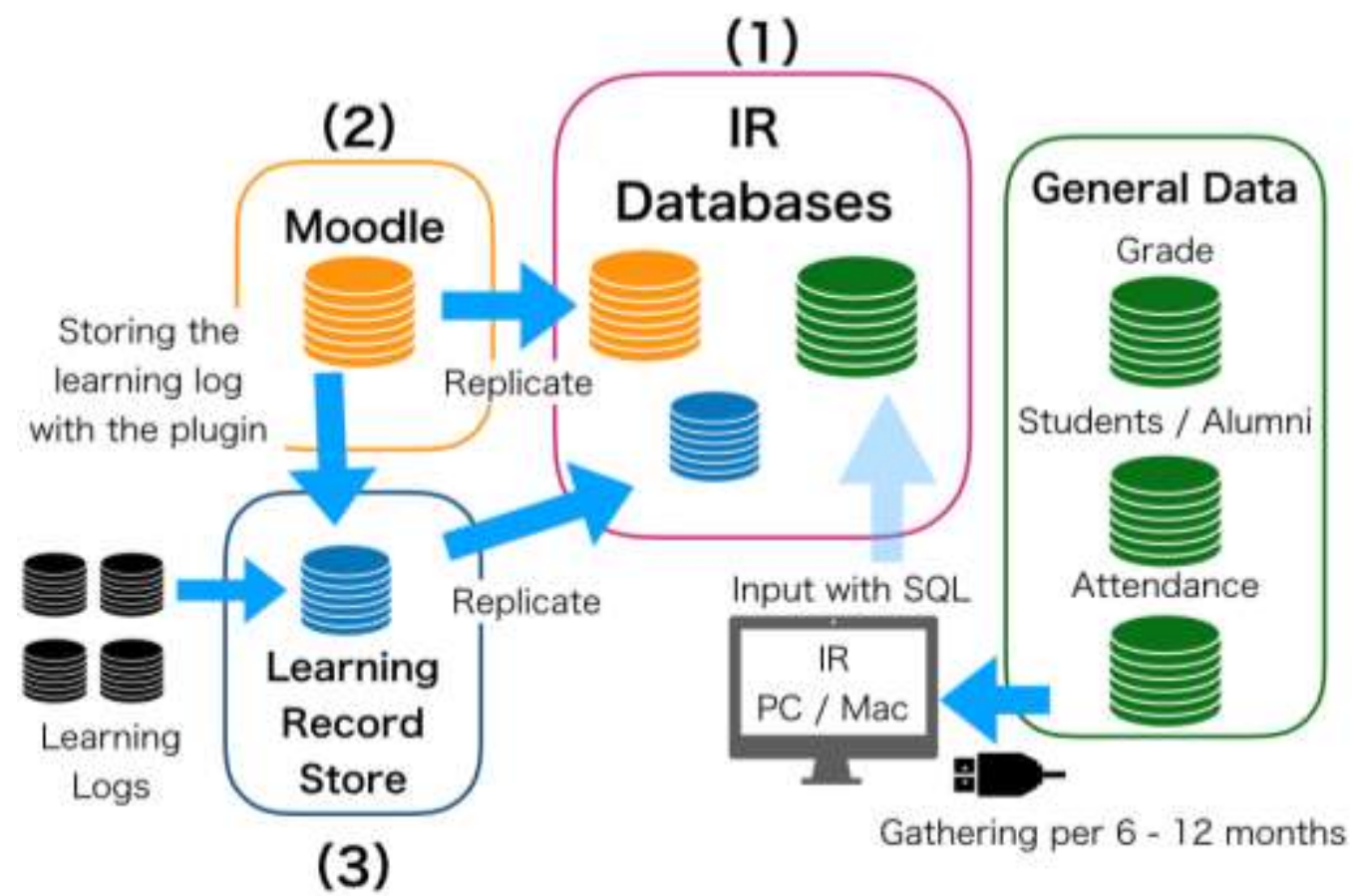

Figure 1: The IR system of JMU

\subsection{IR database}

IR database has several tables including student grades and other statistical information. Some tables have data related to individual students and others have data without information of individual students. The former treats mainly general information about students and the results of their examinations. The latter include syllabus-related subject data and some statistical data, such as the aggregation of the usage of the clinical skills training center.

This section shows some examples of database structures.

\subsubsection{General Information of Students}

Table 1 presents the general information of students, such as ID number, entrance year, gender, and prefecture in which they were born.

Names of students are not included. Since the table should be combined with other tables, student ID is used as the common key column. However, the real student ID number is a student's personal information and hence, it is not suitable for actual, analyzed data. Therefore, a dummy ID number is also stored.

Note that not only student IDs but also the names of prefectures have dummy names too in the database. This is because of the specific situation of JMU, wherein the university takes two or 
three students from each prefecture every year. That is, if the entrance year and prefecture born in is defined, the student is almost specified.

Table 1: Elements in the Student Information Table

\begin{tabular}{|l|l|}
\hline \multicolumn{1}{|c|}{ Items } & \multicolumn{1}{c|}{ Contents } \\
\hline ID & $\begin{array}{l}\text { Unique ID for this table } \\
\text { The ID number of the student, also used as the username of } \\
\text { Moodle } \\
\text { The year when the student joined the university }\end{array}$ \\
$\begin{array}{l}\text { Student Entrance Year } \\
\text { Prefecture }\end{array}$ & $\begin{array}{l}\text { The name of the prefecture in which the student was born } \\
\text { Male / Female }\end{array}$ \\
\hline
\end{tabular}

\subsubsection{Student Year Table}

Table 2 stores students' year-grades. Unfortunately, not all students graduate from the university in six years. Some of them repeat a specific year-grade because of low grades achieved. This table shows the list of those students held back and in which year-grade. Table 2 also effectively defines which year-grades are difficult for students. Such information is needed for curriculum evaluation too.

Table 2: Elements in the Students' Year-Grade Table

\begin{tabular}{|l|l|}
\hline \multicolumn{1}{|c|}{ Items } & \multicolumn{1}{c|}{ Contents } \\
\hline ID & Unique ID for this table \\
Student ID Number & The ID number of the students \\
AD & Actual A.D. year \\
Year-Grade & Students' Year-Grade (1-6) \\
\hline
\end{tabular}

\subsubsection{General Information of Subjects}

Previously, the syllabus was shared only within books and PDFs in JMU. Although using the PDF syllabus is easier than using books for IR because of its searchability, some kinds of information such as goals and objectives of subjects are structured (see Table 3). In addition, since the Japanese medical education has a "Model Core Curriculum (MCC) [9] [10]," each subject should be associated with it. Moreover, these associations, that is, the curriculum mapping, are essential for both students and faculty to find the current topic they are learning or teaching, respectively.

Another problem with the paper-based syllabus is summarizing data. It is difficult to summarize data such as calculating the effort of the faculty. Although the syllabus has a timetable or a schedule for classes, the format of the table is not rigid. Some tables use "merged" cells. Some others use phrases like "same as above." These tables are easy for the students and the faculty to 
read, but they are not suitable for IR data because of the difficulties involved in counting. In addition, the number of classes is different for each subject and thus, the table structure also varies. Thus, another database table is created for the timetable, as shown in Table 4.

For all these reasons mentioned above, some of the syllabus-related data are also stored in the IR database table. The syllabus data are gathered in Word files until 2018 and will soon be converted to Excel files from 2019. Since the Excel file can convert the data into a CSV file, it becomes easier to input the data into the IR database. Note that this table only has the essential information for IR data analytics. Other important elements of the syllabus such as goals and assessments are treated separately. This is mentioned in section 2.2.2.

Table 3: Elements of General Information about Subjects (for IR database)

\begin{tabular}{|l|l|}
\hline \multicolumn{1}{|c|}{ Items } & \multicolumn{1}{c|}{ Contents } \\
\hline ID & Unique ID for this table \\
Subject ID Number & The ID number of the subject \\
Subject Name & The name of the subject \\
Goals & Free-style text on the goals of subjects \\
Objectives & Based on Model Core Curriculum \\
Responsible Faculty & The ID of the faculty responsible for the subject \\
Type of Examination & "Written examination" or "Multiple choice questions" \\
Number of Classes & If subject has continuous classes, "the first and second time \\
& slot," it is counted as two \\
\hline
\end{tabular}

Table 4: Elements of Timetable Information of Subjects (for IR database)

\begin{tabular}{|l|l|}
\hline \multicolumn{1}{|c|}{ Items } & \multicolumn{1}{c|}{ Contents } \\
\hline ID & Unique ID for this table \\
Subject ID Number & ID number of the subject \\
Date of class & Date of class taken as UNIX time \\
Time slot of class & Time slot of class (1-6) \\
Faculty & ID number of faculty taking the class \\
\hline
\end{tabular}

\subsubsection{Students' Grades Table}

Table 5 shows the results of the examinations. Since some students take more than one examination of the same subject in the same semester because of low performing scores previously, the "type of exam" field is set. When students take a retest, 60 is their maximum grades even if their score on the retest is 100 . Thus, the data in the instruction section are also set at 60. The IR data stores the "row" data of the different kinds of examination. This is important to analyze the "actual" performance of students. 
Table 5: Elements of Students' Grades Table

\begin{tabular}{|l|l|}
\hline \multicolumn{1}{|c|}{ Items } & \multicolumn{1}{c|}{ Contents } \\
\hline ID & Unique ID for this table \\
Students ID Number & ID number of the student \\
Subjects ID Number & ID number of the subject \\
Year of exam & Year when examination is taken up, e.g., 2019 \\
Type of exam & E.g., "Mid-term examination" or "retest" \\
Score & Actual score obtained by the student \\
\hline
\end{tabular}

\subsubsection{Attendance Information Table}

JMU uses the student cards with IC-chips to check students' attendance in each class. The attendance data are also stored in the IR database. Since there is a minimum requirement of attendance in each subject, known as the attendance rate, this table is used with the subject table to calculate the percentage of attendance (see Table 6).

Table 6: Elements of the Attendance Information Table

\begin{tabular}{|l|l|}
\hline \multicolumn{1}{|c|}{ Items } & \multicolumn{1}{c|}{ Contents } \\
\hline ID & Unique ID for this table \\
Student ID Number & ID number of the student \\
Subject ID Number & ID number of the subject \\
Number of classes & The number (not the date) of classes \\
Type of attendance & This may show information such as "attended" or "late" \\
\hline
\end{tabular}

\subsubsection{Enrollment Information}

There are several types of information about enrollments. For example, the IR database stores the number of candidates for an entrance examination in each year. The structure of the table is very simple. It has three elements: year, prefecture, and the number of examinees. These data are published on the JMU website where anyone can access it.

\subsubsection{The alumni data}

The alumni data are important for longitudinal analytics. Since JMU alumni will return to the prefecture they were born in and they must engage in rural medicine for at least nine years, these data are also important to analyze the current situation of rural medicine in Japan. These data are also published on the website of JMU (in Japanese). 


\subsubsection{The usage situation of the learning facilities}

The usage situation of the learning facilities is also an essential element for IR. For example, Medical Simulation Center (Jsim47 refers to the simulation center of the Jichi Medical University and 47 refers to the number of prefectures) is one of the important learning facilities in the JMU. All students and faculties can use Jsim 47 not only for official lectures and clinical clerkships but also for self-training. Moreover, Jsim47 is open 24/7 from 2019 and they can use the center even after their schooling or working. This is especially convenient for students as they live in the dormitory and they need not worry about the time when they can use the center.

Jsim 47 has its own reservation system for managing the usage and booking data. The IR section also has a limited connection to the system for downloading and merging the data into IR database. Since the system has multiple database tables, the sample result of the usage report is shown in Figure 2.

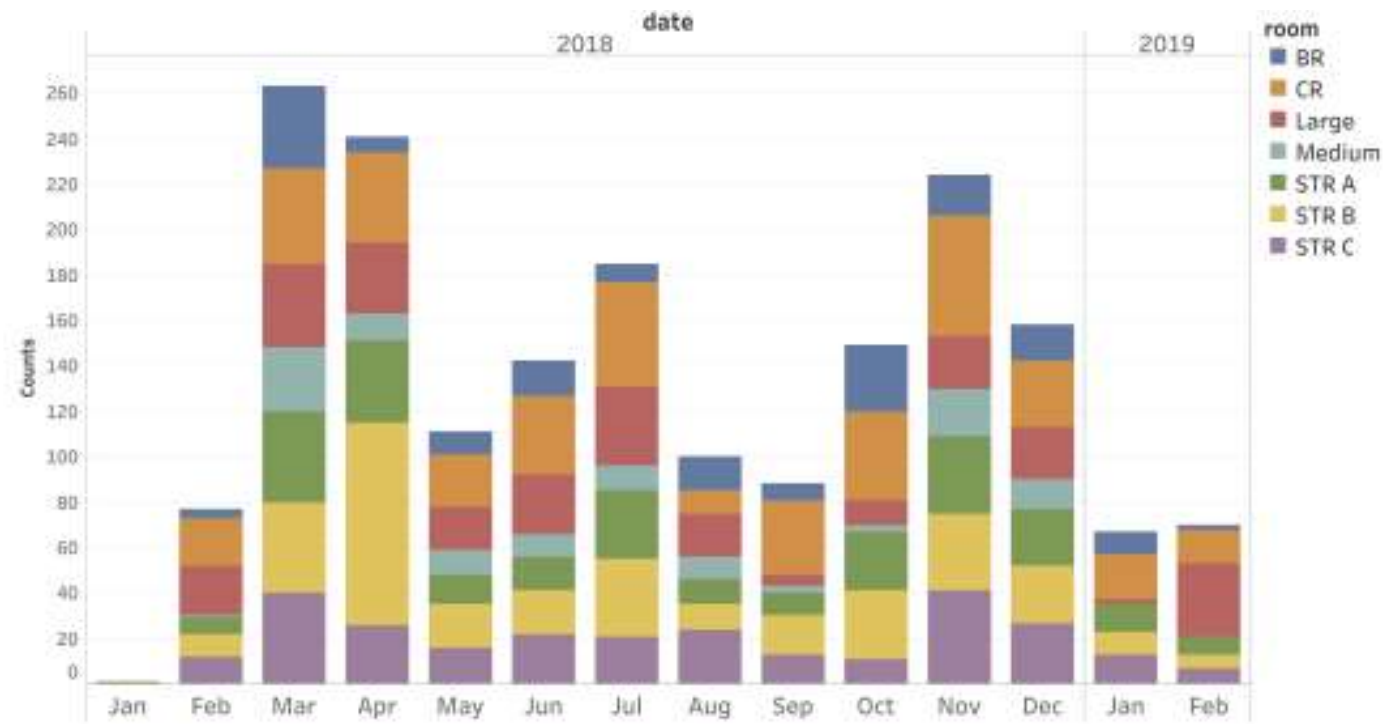

Figure 2: The usage counts of Jsim47 (per room)

\subsection{Moodle: Learning Management System (LMS)}

Although the results of the summative assessments such as "final grades of examinations" are important to trace the student grades year over year, formative assessments of students during the class, experiments, and clinical clerkships are also needed to assess their attitudes. JMU uses the learning management system Moodle to correct these kinds of data. Moreover, the viewing authority constitutes an enormous difference between the IR database and Moodle. 


\subsubsection{General Moodle data}

Moodle can store several learning data, such as logged-in time, page viewing, forum posting, and quiz attempting. However, Moodle is not powerful enough to export "row" data such as loggedin count [11]. Thus, JMU Moodle installed "Configurable Reports" plugin to export the data.

Configurable Reports is the block plugin for data analyzing. The administrator and the manager role of Moodle are able to extract data with SQL. Moodle Docs, the official web document of Moodle, has a list of ad-hoc SQL for exporting whole students' responses to quizzes. Figure 3 shows the visualized data of usage of quizzes in specific course with $R$ and plot.ly.

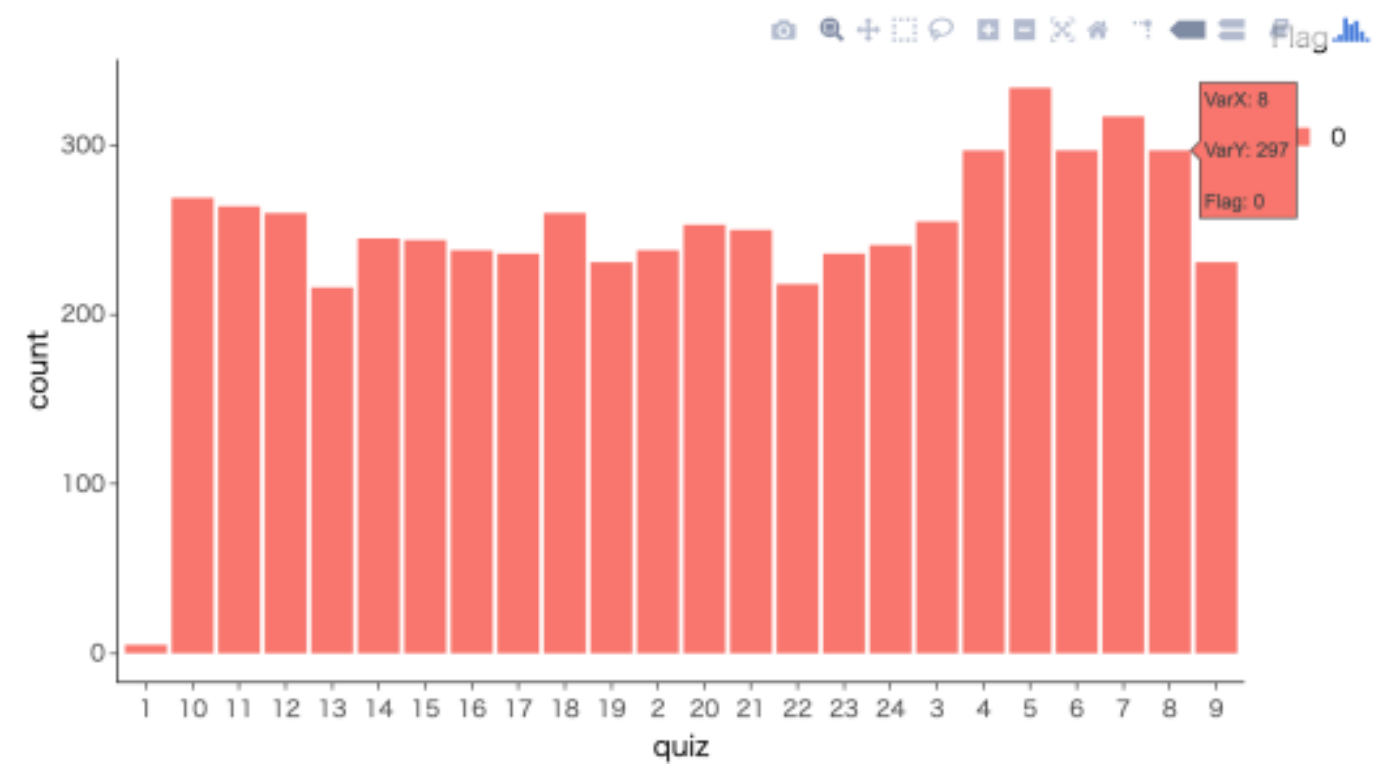

Figure 3: The total counts of trials in the specific quiz module of Moodle

\subsection{2 e-Syllabus}

Since IR database are restricted to most students and faculty, this is not suitable for e-syllabus. Thus, e-syllabus with Moodle is underdeveloped in JMU. The prototype of e-syllabus includes two contents: 1) A list of subjects with goals and objectives, and 2) A mapping of courses with the MCC and JMU diploma policies (DP).

The former is developed using the Moodle database activity. One of the features of the database activity is a simple "database" such as Microsoft Access and FileMaker. Figure 4 shows a sample of the e-syllabus (translated into English). 


\section{e-syllabus 2019(tentative)}

Home / Courses / e-syllabus / e-syllabus zorg/tentative) / Topic 1 / e-syllabus sample / View single

\section{e-syllabus sample}

View list View single Search Addentry Export Templates Fieids Prosets

\begin{tabular}{|c|c|c|c|}
\hline Number & Name & Faculty & Year Grade \\
\hline L-9999 & Introduction to Medicine & Taro Jichi & 1st \\
\hline \multicolumn{4}{|l|}{ Goals } \\
\hline This subject is ... & & & \\
\hline
\end{tabular}

A-2-2-Medicał knowledge and problem-solving ability-Learning modatity

B-4-1-5ocial sciences related to medical practice-Social characteristics required of a physician

Competencies

III-1-3-Continuation of career as the situation demands such as medicine, technology and society

Textbooks

None

References

None

Web Resources

None

How to Grade

Attendance: $10 \%$

Assignments: $30 \%$

Examination: $60 \%$

Examination

MCQ

Learning Contents

Guidance

Theme 001

Theme 002

Figure 4: Sample of e-syllabus with Moodle database activity, objectives, and competencies shows the MCC and DP.

The latter is created using the feature of competencies. Moodle can have competencies as a treestructured data. Each competency can be connected to each course or each activity. The administrator of Moodle is also able to define the stage of completion of competencies, such as "not competent" and "highly competent." 
Table 7: Elements of General Information of Subjects (for Moodle e-syllabus)

\begin{tabular}{|l|l|}
\hline \multicolumn{1}{|c|}{ Items } & \multicolumn{1}{c|}{ Contents } \\
\hline ID & Unique ID for this table \\
Subject ID Number & ID number of the subject \\
Goals & Free-style text on the goals of subjects \\
Objectives & Choices from the lists of MCC (3 to 5) \\
Competencies & Choices from the lists of DP (3 to 5) \\
Texts / References & Information about the textbooks \\
Grading & Grading rules and the percentage of each element, such as \\
& attendance and final examination \\
Contents & List of contents of each class \\
\hline
\end{tabular}

\section{Current Working Topics of IR}

There are some distinctive aspects of medical education, especially in JMU. In this section, the four main topics are described.

\subsection{Enrollment Management}

As mentioned before, JMU takes two or three students from each prefecture every year because of the specialty of the university. This means that the scores on the entrance examination sometimes would not function properly.

Figure 5 shows the distributions of the number of candidates who took up the entrance examination. The figure shows that there are large differences in the numbers; some prefectures have about only 20 while others have more than 100. Since the university must admit 2 to 3 students from each prefecture, there would also be score gaps among candidates. That is, some applicants who score higher in prefecture A (e.g., 85\%) might not gain admission while other applicants who score lower in prefecture B (e.g., 70\%) might gain admission even though they have taken the same examination. 


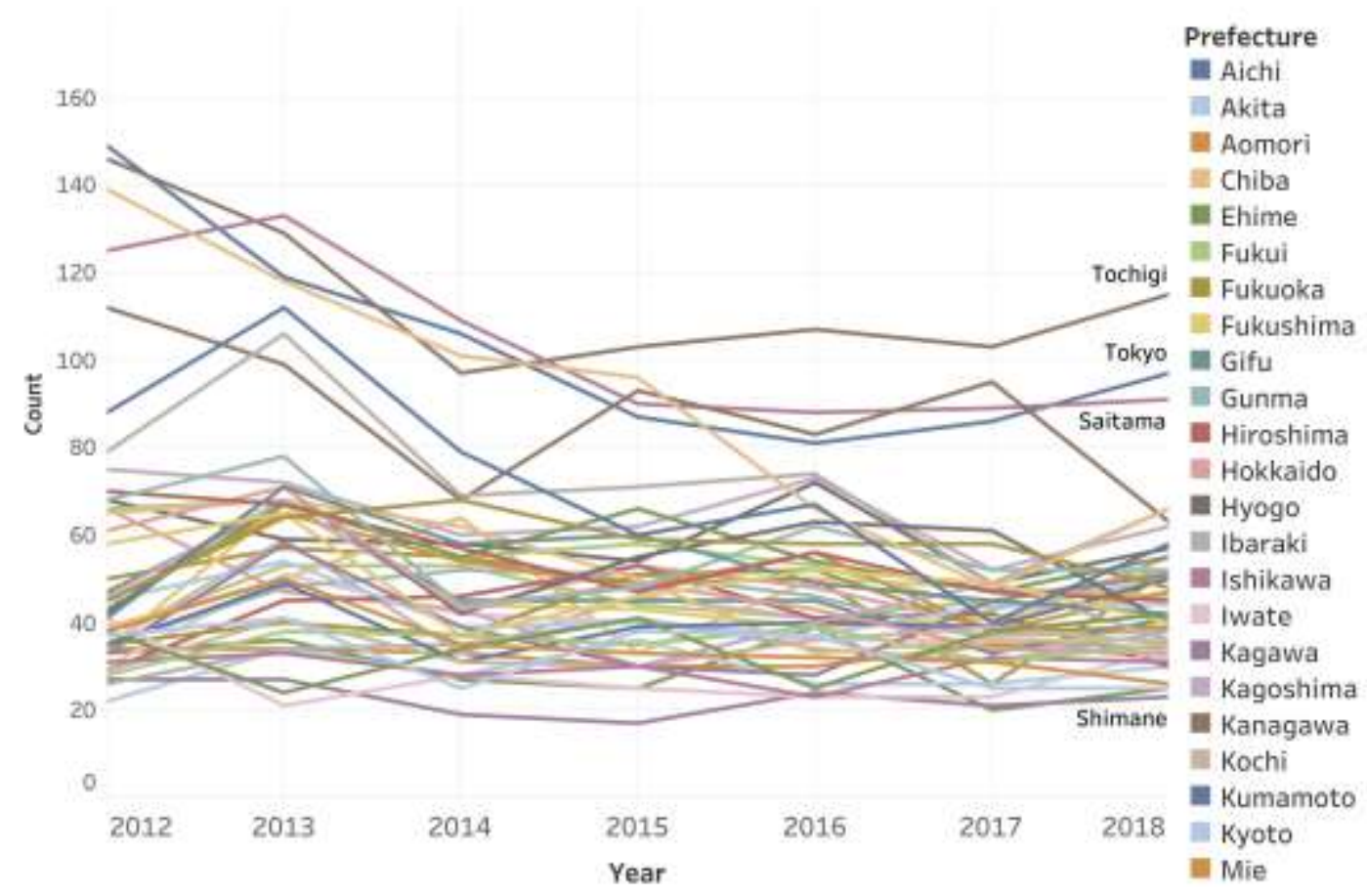

Figure 5: Distribution of the number of candidates, the color of lines shows the prefectures

Although distribution per prefecture is the special interest topic of JMU, other topics such as the distribution of sex and the length of the year spent after high school graduation sometimes hold significant meaning in certifying the equitability and fairness of the entrance examination.

\subsection{Indexes for Institutional Research}

The second topic is indexes for analysis. The "standard" indexes are sometimes not appropriate because of the specialty of medical education.

For example, most subjects are compulsory. Of course, there are some elective subjects such as liberal arts, but medical-specific subjects such as anatomy and clinical medicine are all mandatory. Also, there are many non-classroom lectures such as bed-side learning and PBL (Problem Based Learning). This means that the rates of unit acquisition or attendance for classroom lectures might not be suitable as indexes to consider at-risk students. In other words, new indexes should be considered for medical education.

In JMU, Moodle has been used as the LMS from 2012, especially for first-year students. There are some assignment tasks and materials for self-directed learning. Moreover, some lab courses and bed-side learnings use Moodle as a tool for assessment of attitudes and as a learning portfolio these days. For example, Figure 6 shows the sample distribution of the submission time of quizzes. This figure shows some students doing their task late night. This might have led to short-time sleep and in turn to low performance. These kinds of formative assessment data would be useful for IR, especially for enrollment management as a longitudinal data after the entrance. 


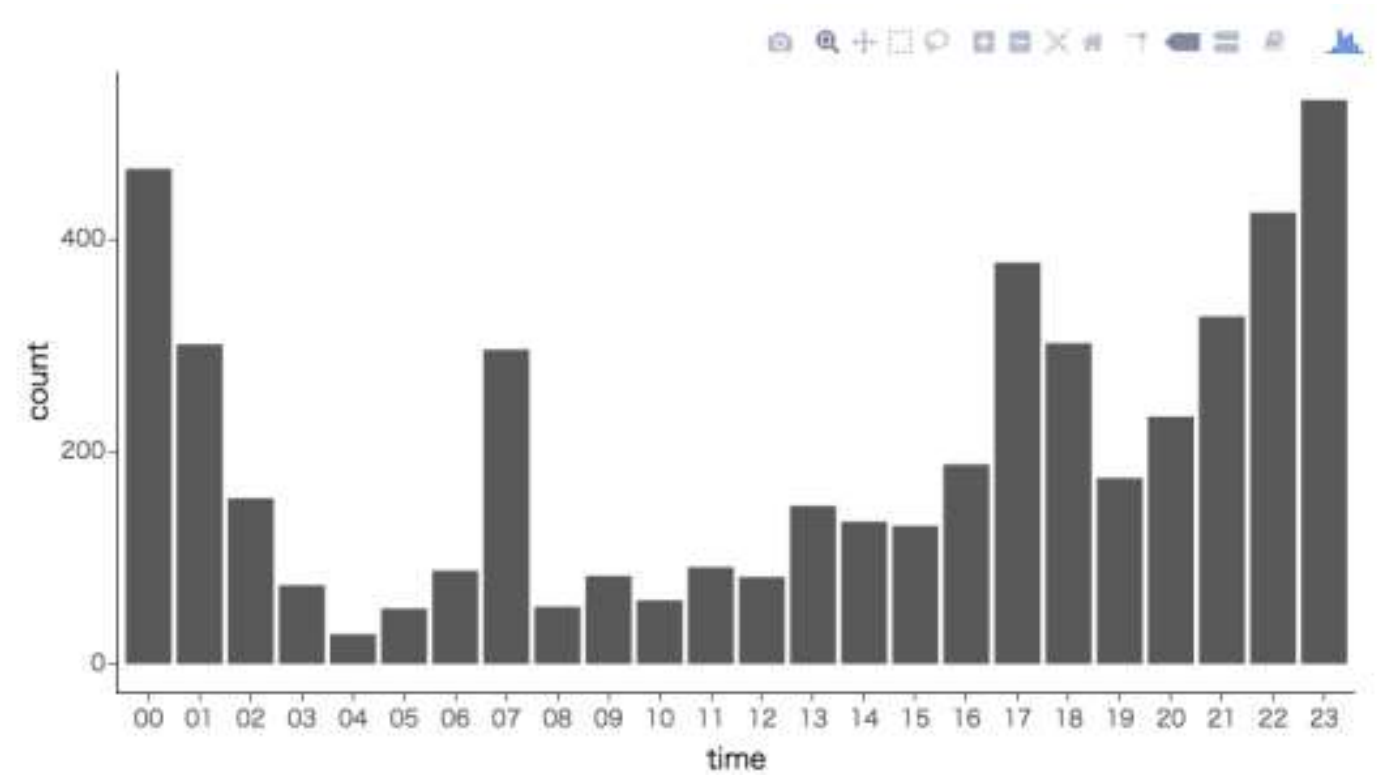

Figure 6: Distribution of submission date and time of assignments on Moodle

\subsection{Learning Analytics}

Previous sections mentioned about IR from the position of the faculty. However, the important role of education deals with students. Although the IR is needed for some academic management such as accreditation, some of the data are based on students' learning results. In fact, there are previous studies about learning analytics with Moodle data in medical education [12] [13]. They might be useful for analyzing and finding at-risk students [14].

If the data can be used for students and faculty as well, this will aid learning support. However, since the IR data treat some sensitive data, they are not suitable for sharing with students, and even with faculty. Thus, the summarized, visualized data sharing structure is underdeveloped in Moodle.

One example is that of viewing learning-completion status. The "objectives" of syllabus are connected to the MCC and the "competencies" are connected to DP in JMU. That is, if students clear some subjects, the related MCC and DP are also cleared to some extent. Thus, it can calculate and visualize the completion rate of $\mathrm{MCC}$ and diploma policies from the completion stage of the subjects.

Note that students have limited access authorization to visualized data; they should be able to access only their own data. When students access Moodle, they use their own ID and password. Thus, the new plugin is developed to check the id number and view only their data.

Furthermore, since Moodle is one of the common open source LMS [15] and is used in several universities and colleges, the methods of IR with learning analytics based on Moodle data would be shareable and useful for other medical universities and colleges. 


\subsection{Establishing the system for sharing visualized data}

The fourth one is about sharing the results. Since educational data are personal information, the data should be handled sensitively. The raw results data of analysis by IR are on the local computer, and the faculty and staff cannot access them directly. Some graphs and anonymous data are accessible via local area network for the convenience of meetings or for committee, but they require the id and password.

Although most graphs on report files such as PDFs are static images, the dynamic graphs are useful for IR such as filtering the data and changing the scale of axes. For example, choosing specific years or terms is needed to analyze and to compare the differences between them. The typical approach to make dynamic graphs is to use business intelligence (BI) tools [16] [17]. However, many BI tools need on-premise or cloud server for sharing the results. As noted before, the data of IR include sensitive information that is not permitted to be uploaded to the cloud server. Also, these servers usually have limits on the number of accounts. This implies that sharing the results of IR via BI server with the faculty is difficult due to the limit on the number of accounts.

Moreover, data protection regulations such as EU GDPR (General Data Protection Regulation) are attracting a lot of attention these days [18]. Since the role of IR is not the assessment of students but the evaluation of the educational system, the educational data would be handled for a purpose other than the original intent. Therefore, students' consent to this must be sought to use their data as needed.

One possible idea to make the sharing system for sharing visualized data is using Moodle. In fact, some previous studies show LMS with visualization for learning analytics and assistance of selfregulated learning in medical education [19] [20]. As mentioned before, plugins of Moodle such as "Configurable Reports" and "Ad-hoc database query" are able to extract row data from the database with SQL. If some improvements are made to the plugin, it would be possible to visualize the data using some other programming languages such as Python and $\mathrm{R}$, as shown in Figure 3.

Another idea is to use open data for sharing contents such as the syllabus. Many universities and colleges disclose and share their syllabus. Thus, it would be possible to share statistical data based on e-syllabus such as the curriculum mapping of DP and MCC for each subject. Since MCC is used commonly in Japanese medical education, visualized data based on MCC can be easily comparable with results of other institutions. Furthermore, this sharing style can be applied to other clinical education fields that have MCC, such as pharmacy education or nursing education.

\subsection{Limitations}

Despite the positive ideas emerging from the establishment of IR, this paper has its limitations too. First, this study is only a case report and mentions only a few results of actual IR data. One of the future tasks on establishing the IR of JMU is to analyze the data and find useful results for educational improvement such as for enrollment management or checking the curriculum map.

Second, the results and discussion focus only on the JMU case. Since there are another 81 medical universities and colleges in Japan, and the JMU has some specific aspects, as is noted in the 
previous section, the generality of the results might be a little weak. The suggested IR system should be compared with other universities as a future task.

Furthermore, this discussion is based only on "IR for medical education" in Japan. Although sometimes IR and learning analytics are considered separately, they share some similar aspects, as noted in the previous section. They mean almost the same when discussing enrollment management and supporting system of learners [21]. Thus, both IR and learning analytics are to be used in the literature review. The different aspects of IR must also considered carefully when the results of this study are applied to other IR.

\section{Conclusion}

In this paper, the current situation of medical education and the needs of educational IR in Japan are described, using a case study of JMU. There are three different databases in JMU for IR data management: (1) MySQL-based IR database with general information of students, including test scores; (2) Moodle, including e-syllabus with database activity module; and (3) LRS, which is currently for storing the data from Moodle. These data can be used for several educational IR, such as certifying the equitability and fairness of the entrance examination. Some of the datasets can be used for learning analytics to support students. Future work would involve analyzing the data to find useful results and compare them to results of other universities. This would help establish indexes for IR in medical education.

\section{Acknowledgments}

This work was supported by "Jichi Medical University Young Investigator Award," "JSPS KAKENHI" (Grant Number 18K02865), and "Health, Labour and Welfare Sciences Research Grants" (Research on Medical ICT and Artificial Intelligence).

\section{References}

[1] Y. Nakamura, Y. Takamiya, M. Saito, K. Kuroko, T. Shiratsuchi, K. Oshima, Y. Ito, and S. Miyake, "A Survey of Palliative Medicine Education in Japan's Undergraduate Medical Curriculum," BMC Palliative Care, vol. 16, 2017, pp.38 doi: 10.1186/s12904-017-0212-1.

[2] Basic Medical Education: Japanese Specifications, WFME Global Standards for Quality Improvement, $\quad$ https://wfme.org/publications/bme-japanese-specifications2015/?wpdmdl=834\&ind=3n0ohF0VvL_14xppNexGcstTmvg7T3g57KgXsQYbu1Vda8LQy4hTi9ipr4bmzeNZA0INs6bClpMGlkIFjmZg Japanese)

[3] Basic Medical Education WFME Global Standards for Quality Improvement, the 2015 revision, https://wfme.org/publications/wfme-global-standards-for-quality-improvementbme/?wpdmdl=831\&ind=98bcn8G7oNLoIkZxyMAQG4Hdo5rerpzpM0gM4wwN4CQDT U6htsKBS943G7pJQGTB

[4] Y. Asada, "Investigation of the Current Situation of Medical Education in Japan Based on the 
Results of Accreditation Based on Global Standards," Proc. 8th IIAI International Congress on Advanced Applied Informatics (IIAI-AAI), 2019, pp. 342-346.

[5] R.D. Howard, G.W. McLaughlin, and W.E. Knight, The Handbook of Institutional Research, Wiley, 2012.

[6] K. Inoue, Y. Hirayama, and M. Igarashi, "A Medical School for Rural Areas," Medical Education, vol. 31, no. 6, 1997, pp. 430-434.

[7] M. Matsumoto, K. Inoue, and E. Kajii, "Long-term Effect of the Home Prefecture Recruiting Scheme of Jichi Medical University, Japan," Rural and Remote Health, vol. 8, no. 3, 2008, pp.1-15.

[8] Y. Asada, "Trends of Institutional Research in Japanese Medical Education: A Case Study of Jichi Medical University," Proc. 7th IIAI International Congress on Advanced Applied Informatics (IIAI-AAI), 2018, pp. 490-492.

[9] Model Core Curriculum for Medical Education in Japan, AY 2016 Revision (in Japanese), http://www.mext.go.jp/component/b_menu/shingi/toushin/_icsFiles/afieldfile/2017/06/28/1 383961_01.pdf

[10] Model Core Curriculum for Medical Education in Japan, AY 2016 Revision (in English), http://www.mext.go.jp/component/a_menu/education/detail/_icsFiles/afieldfile/2018/06/18 /1325989_30.pdf.

[11] M. Saqr, U. Fors, M. Tedre, "How Learning Analytics Can Early Predict Under-achieving Students in a Blended Medical Education Course," Medical Teacher, vol. 39, no. 7, 2017, pp. 757-767.

[12] M. Saqr, "A Literature Review of Empirical Research on Learning Analytics in Medical Education," International Journal of Health Sciences, vol. 12, no. 2, 2018, pp. 80-85.

[13] M. Saqr, U. Fors, and M. Tedre, "How the Study of Online Collaborative Learning Can Guide Teachers and Predict Students' Performance in a Medical Course," BMC Medical Education, vol. 18, no. 1, 2018, pp. 24.

[14] N. Kondo, M. Okubo, and T. Hatanaka, "Early Detection of At-Risk Students Using Machine Learning Based on LMS Log Data," Proc. 6th IIAI International Congress on Advanced Applied Informatics (IIAI-AAI), 2017, pp. 198-201.

[15] edutechnica, LMS Data - Spring 2019 Updates, https://edutechnica.com/2019/03/17/ lms-data-spring-2019-updates/

[16] L.D. McIntosh, C. Zabarovskaya, M. Uhlmansiek, "It's Just (Academic) Business: A Use Case in Improving Informatics Operations with Business Intelligence," Proc. AMIA Jt Summits Transl Sci, 2015, pp. 117-121.

[17] V.K. Ong, "Business Intelligence and Big Data Analytics for Higher Education: Cases from UK Higher Education Institutions," Information Engineering Express, vol. 2, no. 1, 2016, pp. 65-75. 
[18] Home Page of EU GDPR, https://www.eugdpr.org/

[19] T. Treasure-Jones, R. Dent-Spargo, and S. Dharmaratne, "How Do Students Want Their Workplace-based Feedback Visualized in order to Support Self-regulated Learning? Initial Results \& Reflections from a Co-design Study in Medical Education," Proc. European Conference on Technology Enhanced Learning (EC-TEL) 2018, http://ceur-ws.org/Vol2193/: CEUR.

[20] T. Treasure-Jones and R. Dent-Spargo, "How Students Want to See and Use Their Workplace Learning Data: Initial Results from a Co-design Study," Proc. AMEE 2018 abstract book, 2018, pp. 725.

[21] L.D. Roberts, J.A. Howell, K. Seaman and D.C. Gibson, "Student Attitudes toward Learning Analytics in Higher Education: "The Fitbit Version of the Learning World," Frontiers in Psychology, vol.7, 2016, pp. 1959 doi: 10.3389/fpsyg.2016.01959. 